\title{
Epidemiology of breast cancer in women in Jordan: patient characteristics and survival analysis
}

\author{
K. Arkoob, ${ }^{1}$ M. Al-Nsour, ${ }^{2}$ O. Al-Nemry ${ }^{3}$ and B. Al-Hajawi ${ }^{2}$
}

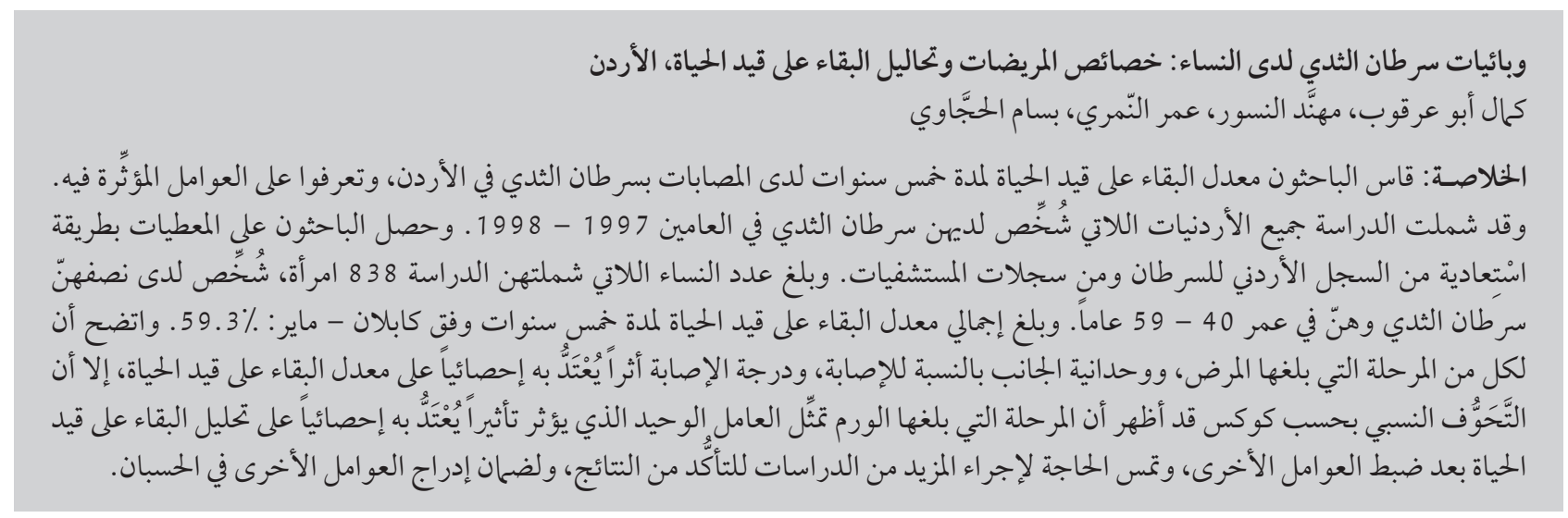

ABSTRACT The 5-year survival rate of female breast cancer cases in Jordan and some of the factors that affected survival were measured. All Jordanian women newly diagnosed with breast cancer during 1997-98 were included. Data were obtained retrospectively from the Jordan Cancer Registry and hospital records. Of 838 women included, half were diagnosed between the ages 40 and 59 years. The overall Kaplan-Meier 5-year survival rate was 59.3\%. Stage, laterality and grade had a significant effect on survival rate. However, Cox proportional regression showed that tumour stage was the only factor that significantly influenced survival analysis after controlling for other factors. Further studies are needed to confirm the results and to ensure the inclusion of other factors.

Épidémiologie du cancer du sein chez les femmes : caractéristiques des patients et analyse du taux de survie en Jordanie

RÉSUMÉ Le taux de survie à cinq ans chez les femmes atteintes d'un cancer du sein en Jordanie et certains des facteurs ayant eu une influence sur la survie ont été mesurés. Toutes les femmes jordaniennes chez lesquelles un nouveau diagnostic de cancer du sein avait été posé en 1997-1998 ont été incluses. Les données ont été obtenues rétrospectivement dans le Registre du cancer jordanien et les dossiers hospitaliers. Pour la moitié des 838 femmes incluses, le diagnostic avait été établi entre 40 et 59 ans. Le taux de survie global à cinq ans par la méthode Kaplan-Meier était de 59,3\%. Le stade, la latéralité et le grade avaient un effet important sur le taux de survie. Toutefois, le modèle de régression à effet proportionnel de Cox a révélé que le stade de la tumeur était l'unique facteur ayant une véritable influence sur l'analyse de la survie après l'élimination d'autres facteurs. Des études supplémentaires sont nécessaires pour confirmer les résultats et garantir l'inclusion d'autres facteurs.

${ }^{7}$ Al-Basheer Hospital, Ministry of Health, Jordan.

${ }^{2}$ Disease Control and Prevention Directorate, Ministry of Health, Jordan (Correspondence to M. Al-Nsour: mohannadnsour973@yahoo.com). 3 Jordan Cancer Registry, Ministry of Health, Jordan.

Received: 08/12/07; accepted: 06/01/09 


\section{Introduction}

Breast cancer is considered to be the most common cancer throughout the world. Statistics show that about 700000 cases are reported annually, about $57 \%$ of them in developing countries [1]. Data from the United States of America indicate that the incidence of breast cancer increases directly with age until 75-80 years [2]. In Jordan, cancer is the second most frequent cause of death after cardiovascular disease [3]. According to official Jordanian statistics, breast cancer was the most common of all cancers in women in the last decade [3], a figure that agrees with the results obtained from different countries in the region $[4,5]$.

The survival rate is one of the most importantmeasures of cancercare, and is a valuable tool for comparisons between countries. Studies of cancer patient survival, using data from population-based cancer registries, are essential for monitoring and evaluating the effectiveness of the diagnosis and treatment of cancer [6]. The higher survival rates being recorded in some developed countries reflect improvements that have taken place in various areas of cancer control, from health education and early diagnosis to treatment and after care [7]. Information about survival rates in Jordan will help us take further preventive and control measures in order to improve the prognosis of patients with different types of cancers. The present study aim to identify the epidemiology of female breast cancer in Jordan in 1997-98; to measure the observed 5-year survival of female breast cancer cases diagnosed in Jordan in the years 1997-98; and to explore some of the factors that affect survival rates, such as age at diagnosis, type, grade and stage of tumour. The majority of studies in Jordan to date have been descriptive, and to the best of our knowledge this is the first study of survival rates at population-based registry level in Jordan.

\section{Methods}

\section{Study design}

This was a descriptive study using data from the Jordan Cancer Registry (JCR). Established in 1996, the JCR is a population-based registry that provides statistics on the incidence of cancer throughout Jordan. JCR obtains its information about patients from governmental and nongovernmental health care facilities and military hospitals throughout the country and from laboratories and the Jordan National Civil Department. Liaison personnel in the main hospitals are responsible for registering and reporting all cases of cancer by completing a special form containing demographic and medical data, which is sent to JCR.

Data collection for the current study lasted more than 3 months. All cases of breast cancer in women that were registered in the JCR and were newly diagnosed during the period 1 January 1997 to 31 December 1998 were included in the study. Cases that could not be verified by a histopathology report were excluded.

\section{Data collection}

Special data collection forms were designed for the study to collect sociodemographic information about the patient (national ID number, name, age at diagnosis, address) and information related to current cancer status (histopathology report, laterality, stage of cancer, grade and stage of the tumour, date of diagnosis, date of last visit, and outcome). The validity and reliability of the study instrument were tested in a pilot study and some variables in the data collection instrument were modified.

Patients were first identified from the JCR registry, after which the medical records and histopathology reports from the reporting hospital were consulted to complete the data. The outcome (alive or dead) was ascertained from the Civil Registration Department using the patient's unique national ID number. Each patient was followed up until dead or alive at the end of data collection period, i.e. for up to 5 years from the date of diagnosis to the cutoff point at 31 December 2003. The follow-up endpoint was death from any cause. Some patients were lost to follow-up as no information was available about them. The final number of patients was 838. Duplication of data was avoided by using the patient's unique national ID number and full (4) names (patient, father, grandfather and family name).

Official approval for the study was obtained from the medical ethics committee of the Ministry of Health before starting data collection. All information about patients was handled under conditions of strict confidentiality and data were analysed anonymously by ID number. No contact was made with patients or their relatives.

\section{Definitions}

Laterality was subdivided into right, left, bilateral and unknown (undetermined or data missing). Histopathology type was categorized into: ductal carcinoma, lobular carcinoma, adenocarcinoma, medullary carcinoma and unknown (undetermined type or data missing). Tumour stage was classified into 4 stages using the American Joint Committee on Cancer TNM [tumour, node, metastasis] criteria: stage I, stage II, stage III, stage VI or unknown (undetermined stage or data missing). Tumour grade was divided into 5 categories: grade 1 (well-differentiated); grade 2 (moderately differentiated); grade 3 (poorly differentiated); grade 4 (undifferentiated) and unknown (undetermined grade or data missing).

\section{Data management and statistical analysis}

Data were entered and analysed using SPSS, version 12. Frequencies of sociodemographic and clinical characteristics of all patients were obtained. The survival rates at 1-year intervals were 
estimated using the actuarial (life-table) method and overall survival rates using exact survival times were estimated using the Kaplan-Meier product limit technique. Log-rank testing was used to test for an association between the variables and the survival rate. $P$-value $<0.05$ was considered statistically significant. Survival probabilities by age, type of cancer, laterality, grade, stage and treatment were obtained. Cox proportional hazard regression analysis was performed to assess the independent effect of different prognostic factors after simultaneously controlling for the effect of potential confounders. Initially all of the following variables were entered in the model: age, type, laterality, grade, stage and treatment modality.

\section{Results}

A total of 838 women with breast cancer were included in this study. The mean age of the patients was 50.2 (standard deviation 12.4) years. Slightly more than half the patients diagnosed fell into the 40-49 and 50-59 years age groups. The left breast was the most commonly affected site (44.6\%). More than three-quarters $(77.5 \%)$ of patients were diagnosed with ductal carcinoma and $41.7 \%$ of tumours were moderately well-differentiated. Almost half (47\%) the patients received combined treatment of surgery, chemotherapy and radiotherapy. More than one-third of patients $(37.6 \%)$ were in stage II at diagnosis.

The period of follow-up ranged from 1 day to 5 years. Just over half the patients (51.4\%) were known to be still alive 5 years after first diagnosis, while $34.8 \%$ were recorded as dead and data were missing for $13.9 \%$ (Table 1).

Calculation of the survival rates at 1-year intervals are presented in Tables 2 and 3 . Using the actuarial method, the 5 -year survival rate for breast cancercases was $59.3 \%$ (Table 2). The percentage of women surviving 1 year after diagnosis

\begin{tabular}{|c|c|c|}
\hline \multicolumn{3}{|c|}{$\begin{array}{l}\text { Table } 1 \text { Distribution of female breast cancer cases diagnosed in Jordan in 1997-98 } \\
\text { by selected characteristics }\end{array}$} \\
\hline Characteristic & No. of cases & $\%$ \\
\hline \multicolumn{3}{|l|}{ Age (years) } \\
\hline$<30$ & 21 & 2.5 \\
\hline $30-39$ & 155 & 18.5 \\
\hline $40-49$ & 224 & 26.8 \\
\hline $50-59$ & 248 & 29.6 \\
\hline $60-69$ & 130 & 15.5 \\
\hline $70+$ & 60 & 7.1 \\
\hline \multicolumn{3}{|l|}{ Laterality } \\
\hline Right & 366 & 43.7 \\
\hline Left & 374 & 44.6 \\
\hline Bilateral & 13 & 1.6 \\
\hline Unknown & 85 & 10.2 \\
\hline \multicolumn{3}{|l|}{ Morphologytype } \\
\hline Ductal & 649 & 77.5 \\
\hline Lobular & 63 & 7.5 \\
\hline Other & 126 & 15.0 \\
\hline \multicolumn{3}{|l|}{ Grade } \\
\hline Grade 1 & 50 & 5.9 \\
\hline Grade 2 & 340 & 41.7 \\
\hline Grade 3 & 288 & 35.5 \\
\hline Grade 4 & 30 & 3.5 \\
\hline Unknown & 130 & 13.1 \\
\hline \multicolumn{3}{|l|}{ Stage } \\
\hline Stage I & 151 & 18.0 \\
\hline Stage II & 315 & 37.6 \\
\hline Stage III & 169 & 20.2 \\
\hline Stage IV & 86 & 10.3 \\
\hline Unknown & 117 & 14.0 \\
\hline \multicolumn{3}{|l|}{ Treatment } \\
\hline Surgery & 72 & 8.5 \\
\hline Surgery \& radiotherapy & 162 & 19.3 \\
\hline Surgery \& chemotherapy & 70 & 8.3 \\
\hline Surgery, radio- \& chemotherapy & 390 & 46.5 \\
\hline Unknown & 144 & 17.1 \\
\hline \multicolumn{3}{|l|}{ Vital status } \\
\hline Alive & 430 & 51.4 \\
\hline Dead & 293 & 34.8 \\
\hline Unknown & 115 & 13.9 \\
\hline
\end{tabular}

was $91.6 \%$, for 2 years $80.1 \%$, for 3 years $70.2 \%$ and for 4 years $65.8 \%$.

The cumulative 5-year survival rates by the Kaplan-Meier method as a function of the different prognostic factors studied (age, type, laterality, grade, stage and treatment) are presented in
Table 3. Figure 1 shows the survival curves for the same variables. The highest 5-year survival rate by age was in the age group $40-49$ years $(67.2 \%)$, and the poorest survival rate in the age group $>30$ years $(43.8 \%)$. The survival rate for patients affected in the right breast 


\begin{tabular}{|c|c|c|c|c|c|c|c|}
\hline $\begin{array}{l}\text { Interval of last } \\
\text { observation } \\
\text { (years) }\end{array}$ & $\begin{array}{l}\text { No. alive at } \\
\text { start of year }\end{array}$ & $\begin{array}{l}\text { No. dying } \\
\text { during year }\end{array}$ & $\begin{array}{l}\text { No. last seen } \\
\text { alive during } \\
\text { year }\end{array}$ & $\begin{array}{l}\text { Effective no. } \\
\text { exposed to risk } \\
\text { of dying }\end{array}$ & $\begin{array}{l}\text { Death rate } \\
\text { during year } \\
(\%)\end{array}$ & $\begin{array}{l}\text { Survival rate } \\
\text { over year } \\
\text { (\%) }\end{array}$ & $\begin{array}{c}\text { Cumulative } \\
\text { survival rate } \\
(\%)\end{array}$ \\
\hline $0-<1$ & 838 & 66 & 115 & 782.5 & 8.4 & 91.6 & 91.6 \\
\hline $1-<2$ & 657 & 82 & 0 & 657 & 12.3 & 87.5 & 80.1 \\
\hline $2-<3$ & 575 & 71 & 0 & 575 & 12.3 & 87.6 & 70.2 \\
\hline $3-<4$ & 504 & 31 & 0 & 504 & 6.1 & 93.8 & 65.8 \\
\hline $4-<5$ & 473 & 65 & 0 & 473 & 13.7 & 86.2 & 59.3 \\
\hline
\end{tabular}

Table 3 Survival rates (Kaplan-Meier analysis) of female breast cancer cases diagnosed in Jordan in 1997-98 by selected characteristics

\begin{tabular}{|c|c|c|c|c|c|}
\hline \multirow[t]{2}{*}{ Characteristic } & \multirow{2}{*}{$\begin{array}{l}\text { No. of } \\
\text { cases }\end{array}$} & \multirow{2}{*}{$\begin{array}{l}\text { No. of } \\
\text { deaths }\end{array}$} & \multicolumn{2}{|c|}{ Survival time (years) } & \multirow{2}{*}{$\begin{array}{l}\text { Cumulative } 5 \text {-year } \\
\text { survival rate (\%) }\end{array}$} \\
\hline & & & Mean & $95 \% \mathrm{Cl}$ & \\
\hline \multicolumn{6}{|l|}{ Age (years) } \\
\hline$<30$ & 15 & 9 & 3.69 & $2.98-4.40$ & 43.8 \\
\hline $30-39$ & 138 & 62 & 3.95 & $3.72-4.18$ & 55.1 \\
\hline $40-49$ & 204 & 67 & 4.26 & $4.07-4.45$ & 67.2 \\
\hline $50-59$ & 207 & 92 & 3.93 & $3.73-4.13$ & 56.7 \\
\hline $60-69$ & 115 & 43 & 4.11 & $3.85-4.38$ & 62.6 \\
\hline $70+$ & 60 & 20 & 3.91 & $3.47-4.36$ & 56.5 \\
\hline \multicolumn{6}{|l|}{ Morphologytype } \\
\hline Ductal & 549 & 226 & 4.07 & $3.95-4.19$ & 58.8 \\
\hline Lobular & 61 & 25 & 3.92 & $3.54-4.30$ & 59.0 \\
\hline Other & 114 & 42 & 4.01 & $3.73-4.29$ & 63.2 \\
\hline \multicolumn{6}{|l|}{ Laterality } \\
\hline Right & 334 & 130 & 4.13 & $3.98-4.28$ & 61.1 \\
\hline Left & 337 & 138 & 4.01 & $3.86-4.17$ & 59.1 \\
\hline Bilateral & 12 & 10 & 2.58 & $1.66-3.51$ & 16.7 \\
\hline Unknown & 41 & 15 & 4.10 & $3.62-4.57$ & 63.4 \\
\hline \multicolumn{6}{|l|}{ Grade } \\
\hline Grade 1 & 50 & 12 & 4.57 & $4.11-5.02$ & 73.9 \\
\hline Grade 2 & 340 & 116 & 4.27 & $4.10-4.45$ & 66.8 \\
\hline Grade 3 & 288 & 168 & 3.58 & $3.35-3.81$ & 43.8 \\
\hline Grade 4 & 30 & 17 & 3.21 & $2.32-4.10$ & 42.9 \\
\hline Unknown & 130 & 48 & 4.17 & $4.01-4.32$ & 63.4 \\
\hline \multicolumn{6}{|l|}{ Stage } \\
\hline Stage I & 151 & 6 & 4.86 & $4.75-4.97$ & 96.0 \\
\hline Stage II & 315 & 80 & 4.27 & $4.12-4.42$ & 71.4 \\
\hline Stage III & 169 & 92 & 3.78 & $3.58-3.98$ & 39.6 \\
\hline Stage IV & 86 & 81 & 2.41 & $2.10-2.71$ & 5.8 \\
\hline Unknown & 117 & 36 & 4.10 & $3.98-4.24$ & 59.3 \\
\hline \multicolumn{6}{|l|}{ Treatment } \\
\hline Surgery & 72 & 30 & 3.89 & $3.36-4.42$ & 58.3 \\
\hline Surgery \& radiotherapy & 162 & 48 & 4.17 & $3.81-4.53$ & 69.0 \\
\hline Surgery \& chemotherapy & 70 & 30 & 3.81 & $3.22-4.40$ & 56.3 \\
\hline Surgery, radio- \& chemotherapy & 390 & 166 & 4.06 & $3.89-4.23$ & 56.8 \\
\hline Unknown & 134 & 19 & 4.41 & $4.05-4.62$ & 82.2 \\
\hline
\end{tabular}

$C l=$ confidence interval. 
(a) Overall survival rates

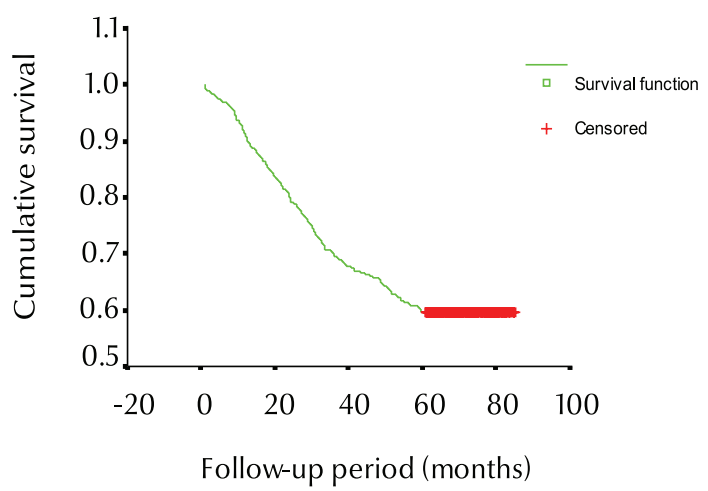

(c) Survival rates by laterality

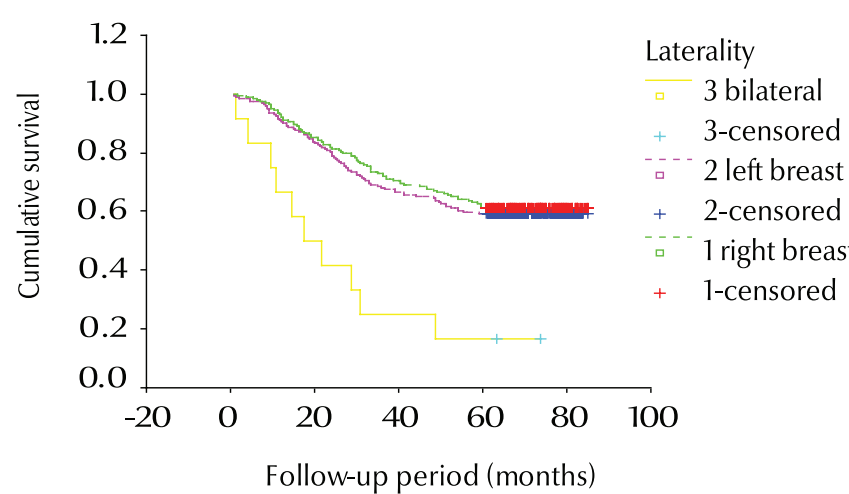

(e) Survival rates by stage

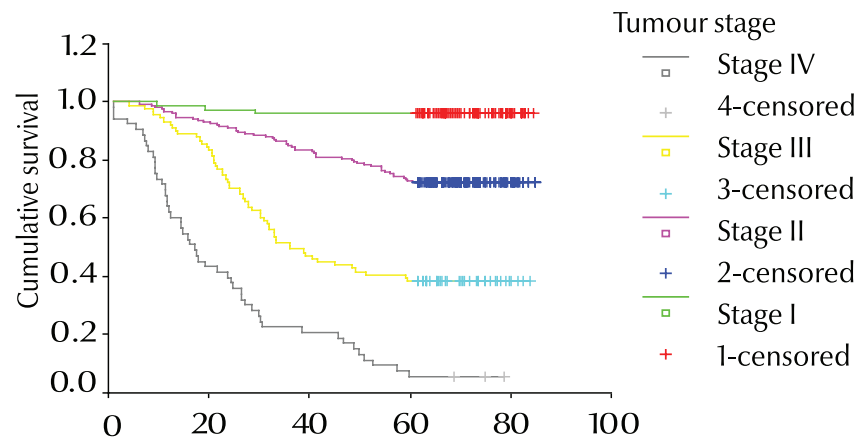

Follow-up period (months) (b) Survival rates by age group

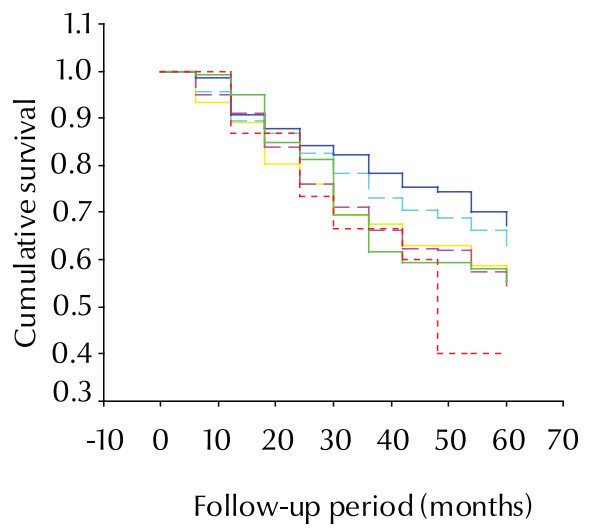

Age group $6>70$ years

+ $560-69$ years

+ $450-59$ years

+ 3 40-49 years

+ 230-39 years

$+1<30$ years

(d) Survival rates by tumour grade

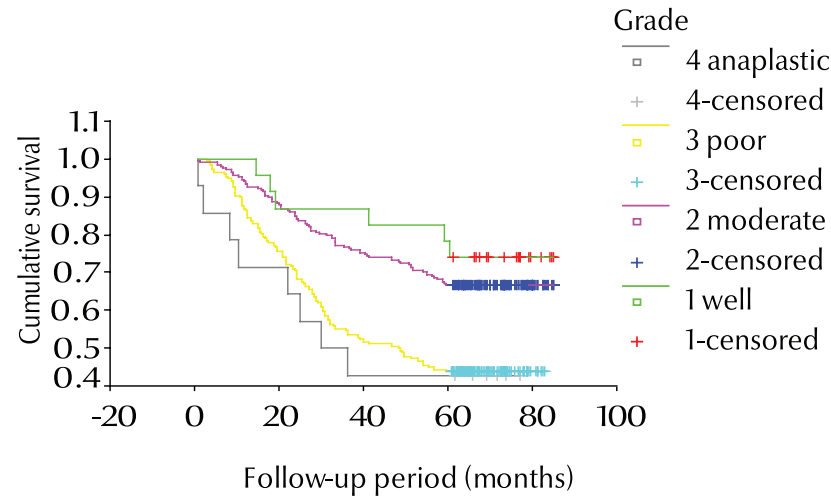

(f) Survival rates by type of treatment

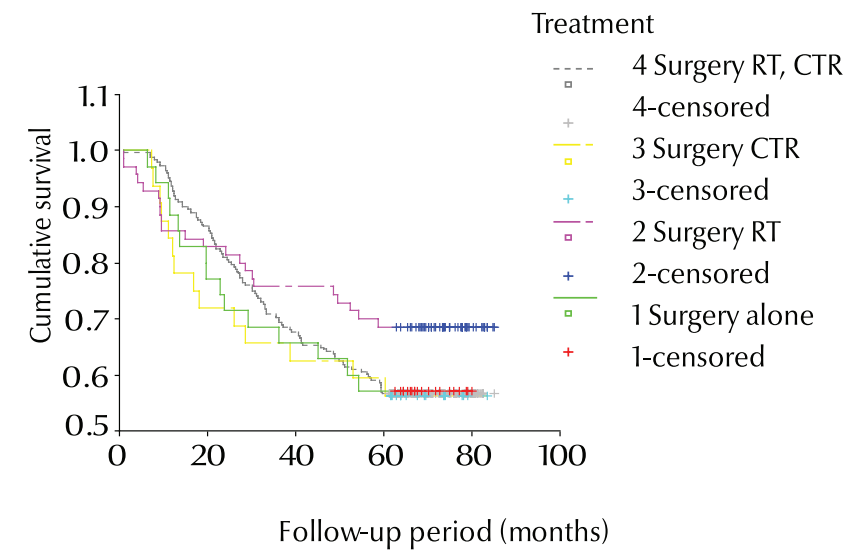

Figure 1 Breast cancer survival rates in women diagnosed in Jordan 1997-98 according to selected variables ( $\mathrm{RT}$ = radiotherapy; $\mathrm{CTR}=$ chemotherapy) 
was $61.1 \%$ and for the left breast was $59.1 \%$; however the survival rate was only $16.7 \%$ for bilateral breast cancer, a difference that was statistically significant $(P<0.001)$. According to the differentiation grade of the tumour, 5-year survival for well-differentiated tumours was $73.9 \%$ compared with $42.9 \%$ for undifferentiated tumours $(P<0.001)$. The 5-year survival rates were $71.4 \%$, $39.6 \%$ and $5.8 \%$ for tumours in stage II, III and IV at diagnosis respectively $(P$ $<0.001$ ). Regarding treatment given to the patients, 5-year survival for patients receiving only surgery was slightly higher (58.3\%) than for those receiving triple therapy of surgery, chemotherapy and radiotherapy $(56.3 \%)$, but the difference was not significant $(P=0.45)$.

Cox proportional hazard regression analysis was performed to assess the independent effect of different prognostic factors after simultaneously controlling for the effect of potential confounders. All of the following variables were initially entered into the model_-age, type, laterality, grade, stage and treatment modality - but only laterality, grade and stage of cancer were kept in the final model. Table 4 shows the hazard ratio and the significance for these 3 variables. According to tumour stage the best survival was found for stage I (hazard ratio of dying $=1.00$ ) compared with the other stages $(P<0.001)$. The grade of the tumour and the laterality did not reach the level of significance in the model.

\section{Discussion}

Our study provides substantial information about the survival rate of women diagnosed with breast cancer in Jordan in 1997-98. While TNM staging at diagnosis, laterality and grade had a significant effect on survival rate, Cox proportional regression analysis showed that after controlling for other factors tumour stage was the only factor that influenced survival. Age and grade had

\begin{tabular}{|c|c|c|c|}
\hline Variable & ExpB & $95 \% \mathrm{Cl}$ & $P$-value \\
\hline \multicolumn{4}{|l|}{ Laterality } \\
\hline Right & 1.00 & - & - \\
\hline Left & 1.06 & $0.73-1.54$ & 0.76 \\
\hline Bilateral & 1.33 & $0.41-4.34$ & 0.63 \\
\hline \multicolumn{4}{|l|}{ Grade } \\
\hline Grade 1 & 1.00 & - & - \\
\hline Grade 2 & 0.74 & $0.30-1.86$ & 0.52 \\
\hline Grade 3 & 0.96 & $0.38-2.42$ & 0.93 \\
\hline Grade 4 & 1.14 & $0.22-5.90$ & 0.88 \\
\hline \multicolumn{4}{|l|}{ Stage } \\
\hline Stage I & 1.00 & - & - \\
\hline Stage II & 6.46 & $2.00-20.88$ & 0.002 \\
\hline Stage III & 17.99 & $5.53-58.56$ & $<0.001$ \\
\hline Stage IV & 72.33 & $21.58-242.4$ & $<0.001$ \\
\hline
\end{tabular}

$C I=$ confidence interval.

no statistically significant association with survival.

Consistent with studies from other countries in the region [8-11], our study showed that the overall 5-year survival rate for breast cancer in Jordan, regardless of stage or grade, was $59.6 \%$. The 1-year rate was $91.6 \%$, the 2-year rate was $80.1 \%$, the 3 -year rate was $70.2 \%$ and the 4 -year rate was $65.8 \%$.

In line with other studies, we found that the overall survival rate was poorer in the age group $<30$ years $(43.8 \%)$ compared with the age group $>70$ years (56.5\%) [12-14]. Lack of competing causes of death, higher frequency of undifferentiated tumours and more cases diagnosed at stage II or III have previously been suggested as the reason for the poor survival experience of young women with breast cancer $[2,15]$. In contrast, a study in the United States of America about breast cancer in young patients aged $<35$ years showed that overall 5-and 10-year survival rates were $65 \%$ and $49 \%$ respectively and concluded that young age was not directly related to the "aggressiveness" of breast cancer [16].

Consistent with a study from Europe [17], the best survival rate in our study was seen in the age group 40-49 years. This could be explained due to access to screening mammography in this age group or due to lower levels of circulating sex hormones, resulting in reduced stimulation of tumour cell growth $[18,19]$.

There was a statistically significant association between survival and laterality, which was $61.1 \%$ in the right breast and $59.1 \%$ in the left breast, while in bilateral cases the 5-year survival was only $16.7 \%$. This is probably explained by the more aggressive disease present in bilateral cases of breast cancer.

The TNM stage proved to be the most significant independent prognostic factor for determining survival. In our study only $55.6 \%$ of cases were diagnosed at stage I and II, whereas in Canada 75\% were diagnosed at stage I and II [11]. Regular mammography combined with regular clinical examination may offer the best opportunity of increasing the proportion of early stage cases detected.

In our study, the 5-year survival rate varied according to stage. This was probably due to the fact that stage reflects the interaction between the host and the tumour. The frequency distribution of 
stage and 5-year survival by stage was similar to data reported by the American Cancer Society [18,20]. However, information from Bahrain showed that that the 5-year survival rate ranged from $87.5 \%$ at stage I to $48 \%$ at stage IV [8], which differs from the results of the present study.

A strength of our study is that it was population-based, comprising virtually all histologically verified cases registered in the JCR, and was therefore not subject to the selection bias of studies that select samples. Another important strength of the study was the ability to investigate the impact of demographic, histological and therapeutic factors on survival in breast cancer. Furthermore, the size of the study was sufficiently large to perform survival analysis across different subgroups of breast cancer cases.

On other hand, some weaknesses of our study should be addressed. First, as in other population-based studies, the medical records were not complete and there was some information missing. Although notification of cases to the JCR is mandatory, the exact cause of death was not recorded in all cases, so we assumed that cancer was the cause of death unless otherwise specified. The exact cause of death in populationbased studies may not always be clearly determined.
Since $30.5 \%$ of the breast cancer cases were diagnosed at stage III and stage IV, great efforts should be made to improve this percentage through a good surveillance system and screening programmes for high-risk groups. Determining the prognosis in cancer cases depends on accurate data on prognostic factors and the appropriate choice of therapeutic and supportive interventions. Further studies are needed to confirm our results in a larger sample and perhaps to ensure the inclusion of other factors such as number of lymph nodes affected, pregnancy history, age at menarche, use of oral contraceptives, menopausal status and oestrogen and progesterone levels.

\section{References}

1. World health report 1988. Life in the 21st century: a vision for all. Geneva, World Health Organization, 1998.

2. Breast cancer incidence and mortality-United States, 1992. Morbidity and Mortality Weekly Report, 1996, 45(39):833-837.

3. Directorate of Information Studies and REsearch. Mortality in Jordan, 2005. Amman, Ministry of Health, 2008.

4. El Saghir NS et al. Age distribution of breast cancer in Lebanon: increased percentages and age adjusted incidence rates of younger-aged groups at presentation. Le Journal Medical Libanais, 2002, 50(1-2):3-9.

5. Omar $\mathrm{S}$ et al. Breast cancer in Egypt. Eastern Mediterranean Health Journal, 2003, 9(3):448-463.

6. Dickman PW, Hakulinen T. Population-based cancer survival analysis (statistics in practice series). New Jersey, John Wiley, 2000.

7. Dickman PW et al. Survival of cancer patients in Finland 1955-1994. Acta Oncologica, 1998:22-25.

8. Fakhro AE et al. Breast cancer: patient characteristics and survival analysis at Salmaniya Medical Complex, Bahrain. Eastern Mediterranean Health Journal, 1999, 5(3):430-439.

9. Al-Moundhri Metal. The outcome of treatment of breast cancer in a developing country-Oman. Breast, 2004, 13(2):139-145.

10. Vahdaninia M, Montazeri A. Breast cancer in Iran: survival analysis. Asian Pacific Journal of Cancer Prevention, 2004, 5(2):223-225.

11. Ravichandran K, Hamdan NA, Dyab AR. Population based survival of female breast cancer cases in Riyadh Region,
Saudi Arabia. Asian Pacific Journal of Cancer Prevention, 2005, 6(1):72-76.

12. Ugant AM et al. Survival of women with breast cancer in Ottawa, Canada: variation with age, stage, histology, grade and treatment. British Journal of Cancer, 2004, 90, 1138-1143.

13. Berrino F et al., eds. Survival of cancer patients in Europe: the EUROCARE study. Lyon, International Agency for Research on Cancer, 1995 (IARC Scientific Publications No.132).

14. Sant $\mathrm{M}$ et al. Survival of women with breast cancer in Europe: variation with age, year of diagnosis and country. The EUROCARE Working Group. International Journal of Cancer, 1998, 77:679-683.

15. Bonnier $\mathrm{P}$ et al. Age as prognostic factor in breast cancer: relationship to pathologic and biologic features. International Journal of Cancer, 1995, 62(2):138-144.

16. Sariego J et al. Breast cancer in young patients. American Journal of Surgery, 1995, 170(3):243-245.

17. Celko AM. Breast cancer epidemiology in the Czech Republic. Central European Journal of Public Health, 1996, 4(2):106-109.

18. Coebergh JWW et al. Survival of adult cancer patients in Europe diagnosed from 1978-1989: the EUROCARE II study. European Journal of Cancer, 1998, 34:2137-2278.

19. Gizlice Z. Breast cancer incidence, mortality and survival in North Carolina. SCHS Studies, 1997, September (No. 108).

20. Breast cancer facts and figures 1996/1999-2000. American Cancer Society [website] (www.cancer.org/statistics/96bcffsurv. html, accessed 3 April 2010). 